\title{
Gastric-and-intestinal mixed endocrine cell phenotypic expression of carcinoid tumors in the rectum
}

\author{
YOSHIKAZU HIRATA ${ }^{1}$, TSUTOMU MIZOSHITA ${ }^{1}$, TAKASHI MIZUSHIMA ${ }^{1}$, TAKAYA SHIMURA ${ }^{1}$, \\ YOSHINORI MORI ${ }^{1}$, EIJI KUBOTA ${ }^{1}$, TSUNEYA WADA ${ }^{1}$, NAOTAKA OGASAWARA ${ }^{1}$, \\ SATOSHI TANIDA $^{1}$, HIROMI KATAOKA ${ }^{1}$, MAKOTO SASAKI ${ }^{1}$, TAKESHI KAMIYA ${ }^{1}$, \\ TETSUYA TSUKAMOTO ${ }^{2}$, MASAE TATEMATSU ${ }^{2}$ and TAKASHI JOH ${ }^{1}$ \\ ${ }^{1}$ Department of Gastroenterology and Metabolism, Nagoya City University Graduate School of Medical Sciences, \\ 1-Kawasumi, Mizuho-cho, Mizuho-ku, Nagoya 467-8601, ${ }^{2}$ Division of Oncological Pathology, Aichi Cancer \\ Center Research Institute,1-1 Kanokoden, Chikusa-ku, Nagoya 464-8681, Japan
}

Received June 24, 2008; Accepted September 1, 2008

DOI: $10.3892 /$ or_00000196

\begin{abstract}
We have previously demonstrated that gastric and intestinal endocrine cell (End-cell) marker expression is important for assessment of the histogenesis of endocrine cell tumors. However, the End-cell phenotypes of carcinoid tumors in the rectum remain largely unclear. We therefore examined marker expression of rectal carcinoid tumors. We evaluated 20 rectal carcinoid tumors (as well as 8 from the stomach for comparison) phenotypically, using gastrin, gastric inhibitory polypeptide (GIP) and glucagons-like peptide-1 (GLP-1) as End-cell markers. Rectal carcinoid tumors were divided into 3 endocrine-gastric (e-G), 16 endocrine-gastric-and-intestinal mixed (e-GI), 1 endocrineintestinal (e-I), and 0 endocrine-null (e-N) types, thus 19 (e-G+ e-GI types, 95\%) had gastric phenotypic expression, while 17 (e-GI+ e-I types, 85\%) harbored intestinal elements. Stomach carcinoid tumors were classified as 6 e-G and 2 e-N types, respectively. In conclusion, most rectal carcinoid tumors exhibited the e-GI type, suggesting the importance of gastric End-cell marker expression for histogenesis of the rectal carcinoid tumors. Further studies of pathological and biological analyses are needed to clarify the histogenesis of the carcinoid tumors.
\end{abstract}

\section{Introduction}

Histologically and biologically, neuroendocrine tumors are divided into carcinoid tumor and endocrine cell carcinoma (1). Regarding the pathological classifications of neuroendocrine

Correspondence to: Dr Tsutomu Mizoshita, Department of Gastroenterology and Metabolism, Nagoya City University Graduate School of Medical Sciences, 1 Kawasumi, Mizuho-cho, Mizuho-ku, Nagoya 467-8601, Japan

E-mail: tmizoshi@med.nagoya-cu.ac.jp

Key words: carcinoid tumors, endocrine-gastric-and-intestinal mixed type, gastrin, glucagon-like peptide-1 tumors, there are several classifications such as WHO classification of digestive tumors (2), TNM staging (3), and Guideline for the management of gastroenteropancreatic neuroendocrine (including carcinoid) tumors (4). However, the histogenesis of neuroendocrine tumors has remained unclear.

From analyses of 8305 lesions (5), it has been concluded that most carcinoid tumors $(73.7 \%)$ occur in the gastrointestinal tract. We have previously demonstrated that gastric and intestinal endocrine cell (End-cell) marker expression is important for assessing the histogenesis of endocrine cell tumors in the stomach (6). Regarding gastric and intestinal End-cell markers, gastrin is predominantly detectable in the pyloric glands of the stomach, while gastric inhibitory polypeptide (GIP) and glucagon-like peptide-1 (GLP-1) are characteristic of the small intestine and colon (7-11). Gastrin is thus a marker of the gastric End-cell, whereas GIP and GLP-1 are typical intestinal End-cell markers (7-11), so that endocrine tumors can be classified as endocrine-gastric (e-G type), endocrine-gastric-and-intestinal mixed (e-GI type), endocrine-intestinal (e-I type), and endocrine-null (e-N type) types (6). In the stomach, carcinoid tumors express chromogranin $\mathrm{A}(\mathrm{CgA})$ and End-cell differentiation markers but have no exocrine cell (Exo-cell) phenotype, and most lesions exhibit an e-G type, suggesting progenitor cells specializing towards an End-cell lineage in the glandular ducts $(1,6,12,13)$. However, to our knowledge, there have hitherto been no data on the gastric and intestinal End-cell phenotypic classification of carcinoid tumors in the large intestine, especially in the rectum.

In the present study, we therefore compared rectal and stomach carcinoid tumors histologically and phenotypically, using gastric (gastrin) and intestinal (GIP, GLP-1) End-cell markers, and Caudal-related homeobox gene $(\mathrm{Cdx}) 2$, an intestinal specific gene.

\section{Materials and methods}

Samples and tissue collection. We examined 20 rectal and 8 stomach carcinoid tumors endoscopically and surgically 
Table I. Antibodies for immunohistochemistry.

\begin{tabular}{lll}
\hline Antibodies & Clonality & Dilution \\
\hline Anti-human chromogranin A (344-374) & Polyclonal & $1: 1000$ \\
Anti-human gastrin 34 (1-15) & Polyclonal & $1: 1000$ \\
Anti-human gastric inhibitory polypeptide & Polyclonal & $1: 2000$ \\
Anti-human glucagon-like peptide-1 (7-36) & Polyclonal & $1: 1000$ \\
Anti-human caudal-related homeobox gene (CDX2-88) & Monoclonal & Prediluted kit \\
\hline
\end{tabular}

Y, Yanaihara Institute, Fujinomiya, Japan; B, BioGenix, San Ramon, CA, USA.
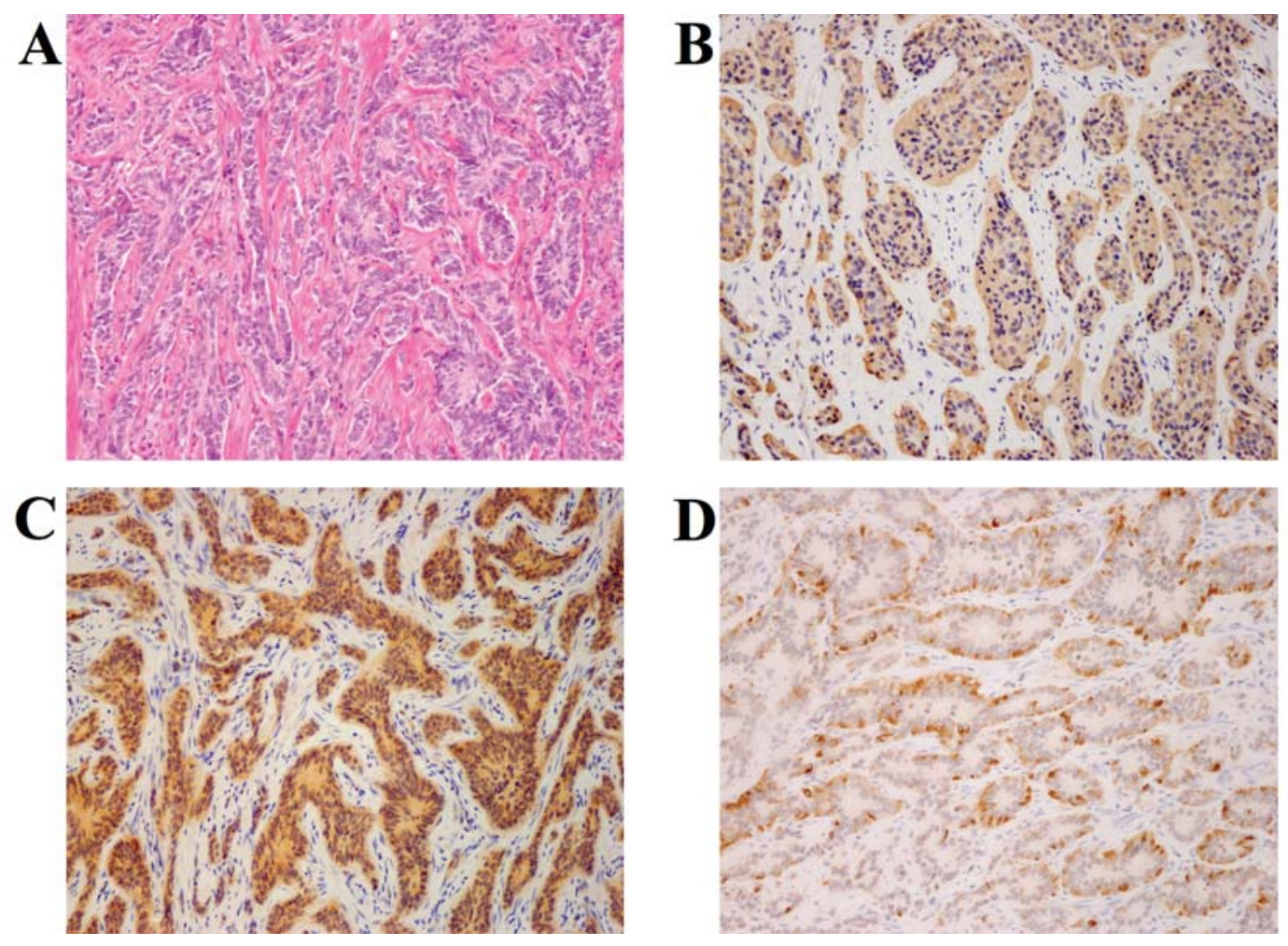

Figure 1. Rectal carcinoid tumors: typical expression of CgA, gastrin and GLP-1. (A) H\&E staining. (B) CgA is apparent in the cytoplasm of tumor cells. (C) gastrin is positive in the cytoplasm of tumor cells. (D) GLP-1 is apparent in the cytoplasm of tumor cells (original magnification, $\mathrm{x} 200$; CgA, chromogranin A; GLP-1, glucagons-like peptide-1).

resected at Nagoya City University Hospital and several associated hospitals between 1996 and 2004. A carcinoid is defined morphologically as a well differentiated neoplasm of the diffuse endocrine system as previously described (6). We defined the term carcinoid tumor according to the WHO classification of digestive tumors (2), and we examined carcinoid tumors as neuroendocrine tumors that had low grade malignancy histologically. In addition, each carcinoid tumor was classified according to the recent WHO classification (14) and TNM staging (3).

All specimens were fixed in $10 \%$ buffered formalin. Carcinoid tumors along with adjacent non-neoplastic mucosa were cut serially into 5-mm slices in parallel and embedded in paraffin, and then stained with hematoxylin and eosin for histological examination.
Immunohistochemistry. Immunohistochemical staining was carried out with antibodies against the antigens listed in Table I $(6,11)$. For gastric and intestinal End-cell markers, we used normal gastric mucosa and normal ileum as positive and negative controls, and vice versa. The precise procedures for immunohistochemical techniques were as previously described $(6,11,15-17)$. Briefly, 4 mm-thick consecutive sections were deparaffinized and hydrated through a graded series of alcohols. After inhibition of endogenous peroxidase activity by immersion in $3 \% \mathrm{H}_{2} \mathrm{O}_{2}$ /methanol solution, antigen retrieval was achieved by heating in $10 \mathrm{mM}$ citrate buffer $\left(\mathrm{pH}\right.$ 6.0) in a microwave oven for $10 \mathrm{~min}$ at $98^{\circ} \mathrm{C}$. Then, sections were incubated with primary antibodies. After thorough washing in phosphate-buffered saline (PBS), they were next incubated with biotinylated secondary antibodies, 


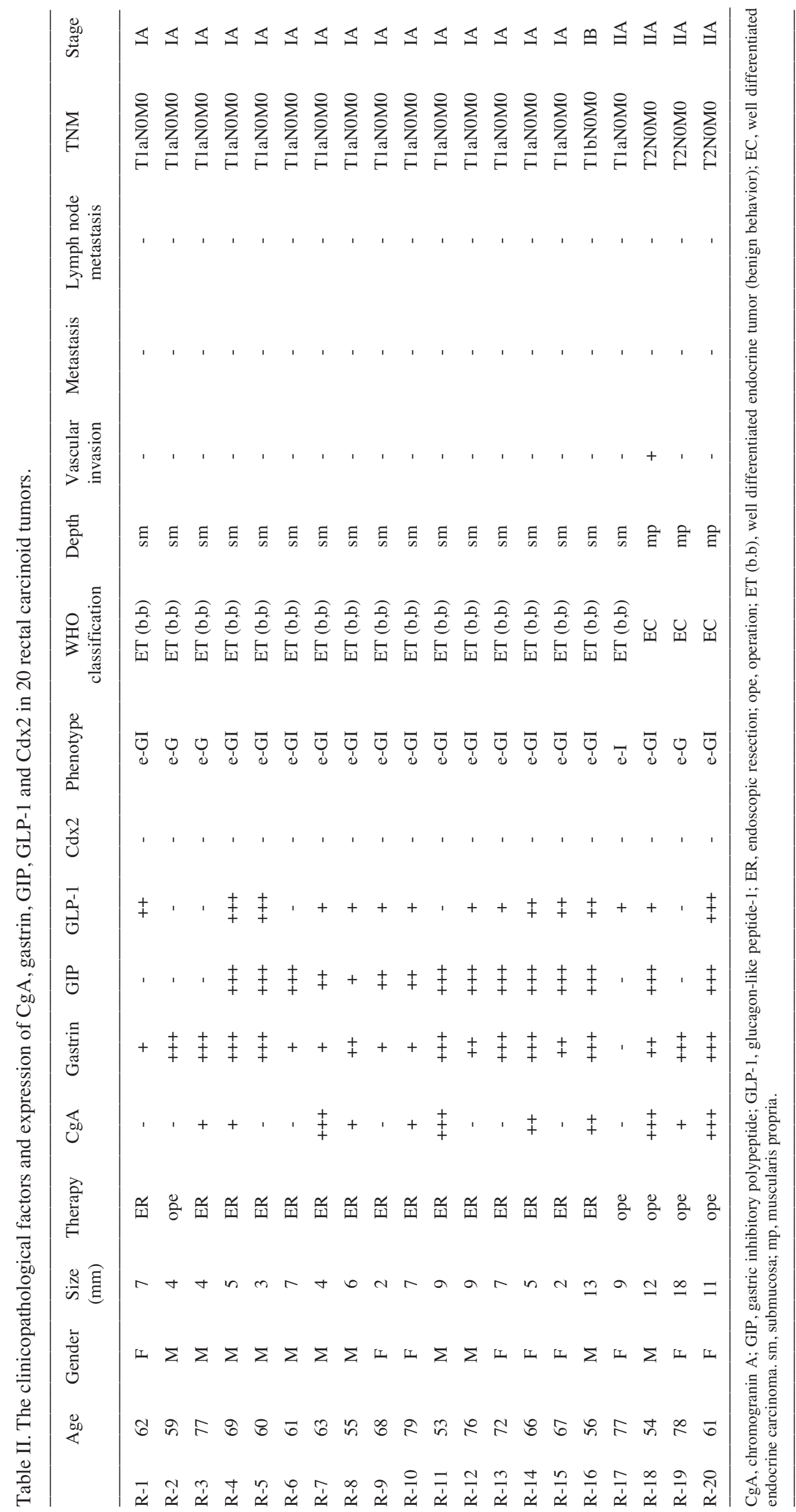




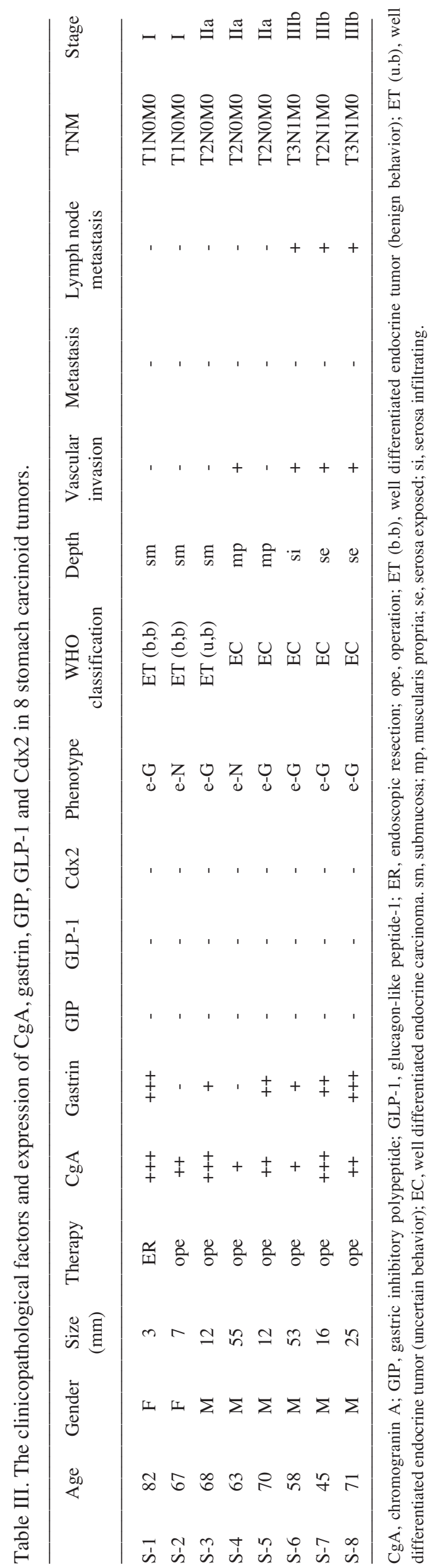

Table IV. Phenotypic classification in stomach and rectal carcinoid tumors.

\begin{tabular}{lrrrrr}
\hline & e-G & e-GI & e-I & e-N & Total \\
\hline Rectal carcinoid tumors & 3 & 16 & 1 & 0 & 20 \\
Stomach carcinoid tumors & 6 & 0 & 0 & 2 & 8 \\
\hline
\end{tabular}

and then with avidin-biotin horseradish peroxidase complexes (Vectastain Elite ABC kit, Vector Laboratories, Inc., Burlingame, CA, USA). Finally, immune complexes were visualized by incubation with $0.01 \% \mathrm{H}_{2} \mathrm{O}_{2}$ and $0.05 \%$ 3,3'-diaminobenzidine tetrachloride (DAB). Nuclear counterstaining was accomplished with Mayer's hematoxylin.

Two independent researchers (Y.H. and T.M.) judged the histology and immunohistochemical staining of the End-cell markers and Cdx2. Reactivity was scored according to the percentage of positively stained tumor cells in the section areas on a 3 -point-scale: score $0(-),<10 \%$; score $1(+), 10-$ $33 \%$; score $2(++), 34-66 \%$; score $3(+++), 67-100 \%$. A result was considered positive $(+)$ with a score of $\geq 1$. When $<10 \%$ of tumor cells stained, immunostaining was considered negative $(6,18)$.

Phenotypic classification of tumors. The carcinoid lesions were classified as e-G type or e-I type, respectively, with at least one gastric or intestinal End-cell phenotype, and e-GI type when both gastric and intestinal End-cell markers were present. Those showing neither gastric nor intestinal phenotypic expression were grouped as e-N type, as previously described (6).

\section{Results}

Clinicopathological factors for rectal carcinoid tumors. Data on clinicopathological factors of 20 rectal carcinoid lesions and results of immunohistochemistry are shown in Table II. Eleven patients were men and 9 were women; they ranged in age from 53 to 79 years (mean $\pm \mathrm{SD}, 65.7 \pm 8.6$ ). Tumor diameters ranged from 2 to $18 \mathrm{~mm}$ (mean $\pm \mathrm{SD}, 7.2 \mathrm{~mm} \pm 4.1$ ). Of the total, 15 were treated by endoscopic resection (ER) and the other 5 by surgical resection. According to the recent WHO classification (14), 17 and 3 lesions were classified as well differentiated neuroendocrine tumors and well differentiated neuroendocrine carcinoma. The lesions had no Exocell marker expression such as MUC5AC, MUC6, and MUC2 (data not shown).

Clinicopathological factors for stomach carcinoid tumors. Data on clinicopathological factors of 8 stomach carcinoid lesions (6 in men and 2 in women) and results of immunohistochemistry are shown in Table III. The age range was from 45 to 82 years (mean $\pm \mathrm{SD}, 65.5 \pm 10.8$ ) and diameters ranged from 3 to $55 \mathrm{~mm}$ (mean $\pm \mathrm{SD}, 22.9 \mathrm{~mm} \pm 20.3$ ). One lesion was treated by ER and 7 by surgical resection. According to the recent WHO classification of endocrine tumors (14), 3 and 5 lesions were classified as well differentiated neuroendocrine tumors and well differentiated 
neuroendocrine carcinoma. The lesions had no Exo-cell marker expression (data not shown).

Phenotypic classification of carcinoid tumors in the rectum and stomach. Results for phenotypic expression of gastric and intestinal End-cell markers are shown in Fig. 1 and Tables II and III. In the rectal carcinoid tumor cases, all 20 lesions had the expression of at least one End-cell marker, expression of gastrin, GIP, and GLP-1 being found in 19 (95\%), $15(75 \%)$ and $15(75 \%)$, respectively. Regarding Cdx2, nuclear staining was lacking, but cytoplasmic expression was found in 11 cases (55\%) (data not shown). The lesions were divided phenotypically into $3 \mathrm{e}-\mathrm{G}, 16 \mathrm{e}-\mathrm{GI}$, 1 e-I, and 0 e-N types, 19 (e-G+ e-GI types, 95\%) having gastric phenotypic expression, while 17 (e-GI+ e-I types, $85 \%$ ) harbored intestinal elements (Table IV).

All 8 carcinoid tumors of stomach were positive for $\mathrm{CgA}$, 6 featuring expression of at least one End-cell marker. Expression of gastrin, GIP, and GLP-1 was found in $6(75 \%)$, $0(0 \%)$ and $0(0 \%)$ lesions, respectively. None was $\mathrm{Cdx} 2$ positive. Phenotypically, there were 6 e-G, 0 e-GI, 0 e-I, and 2 e-N types. Most stomach carcinoid tumors were classified as gastric and none exhibited intestinal End-cell marker expression (Table IV).

\section{Discussion}

The present study provided clear evidence that the majority of rectal carcinoid tumors $(19 / 20,95 \%)$ exhibit gastric End-cell marker expression. Previous studies demonstrated that gastrin positivity was only $3-14 \%$ in the rectal carcinoid tumors $(19,20)$ but the discrepancy might depend on the antibodies used. Raju et al (19) used a polyclonal antibody purchased from Dako Co., while Federspiel et al (20) applied an antibody from Immunonuclear Co. In the present study, we used a polyclonal antibody purchased from Yanaihara Institute. Secondly, differences in immunohistochemical methods could influence the results, especially regarding the incubation time with primary antibodies (overnight in our study vs. $30 \mathrm{~min}$ in the earlier investigations).

The fact that most stomach carcinoid tumors $(6 / 8,75 \%)$ exhibited the e-G type is in line with our previous data (6). Several studies have indicated an origin from a progenitor cell specializing towards the End-cell lineage in gastric glandular ducts exhibiting e-G type $(1,6,12,13)$. Most conventional rectal carcinoid tumors appear to arise from localized areas of crypt cell proliferation rather than from diffuse areas of intraepithelial endocrine cell hyperplasia (21). Furthermore, they are heterogeneous populations of endocrine cells rather than a monoclonal population of cells with each cell expressing a multiplicity of hormones (21). Carcinoid tumors have been considered to be of endodermal origin arising deep in the gastrointestinal mucosa, from cells known as dispersed endocrine cells (22). Taking into account the previous studies and our present data, we therefore consider that the e-I type rectal carcinoid tumors might originate from a progenitor cell specializing towards the End-cell lineage in the normal rectal glandular ducts, in which the intestinal but not gastric End-cell markers are expressed. However, the development of e-GI and e-G type rectal carcinoid tumors can not be so simply explained. Regarding the gastric phenotypic expression in rectal glandular ducts environment, Koike et al (23) reported that hyperplastic polyps have both gastric and intestinal Exo-cell marker expressions such as MUC5AC, MUC6, and MUC2 in the rectum. Hirono et al (24) also revealed that rectal hyperplastic polyps and serrated adenoma showed bidirectional gastric (foveolar and pyloric gland) differentiation. If these facts of the Exo-cell lineage apply to the Endcell lineage, some of e-GI type rectal carcinoid tumors may occur from the progenitor cells specializing towards the Endcell lineage in the glandular ducts exhibiting e-GI type. A progenitor cell specializing towards the End-cell lineage in a rectal glandular duct may harbor not only intestinal but also inherently gastric End-cell marker expression. Further studies of pathological and biological analyses are needed to clarify the histogenesis of the carcinoid tumors.

In our present series, no $\mathrm{Cdx} 2$ nuclear staining was detected in any stomach or rectal carcinoid tumor (Tables II and III). Jaffee et al (25) reported that $\mathrm{Cdx} 2$ in carcinoid tumors is a marker of midgut origin, while we evaluated the $\mathrm{Cdx} 2$ expression of the carcinoid tumors in the rectum as hindgut. There may be other homeobox genes that are associated with intestinal End-cell marker expression in hindgut origin, especially the rectum. Jenny et al (26) have previously demonstrated that neurogenin-3 is required for endocrine cell fate specification in multipotent intestinal progenitor cells, whereas gastric endocrine development can be either neurogenin-3 dependent or independent. Schonhoff et al (27) reported that MATH1 and neurogenin-3 restrict stem cells to the endocrine lineage, whereas the transcription of specific hormones is regulated by several late acting transcription factors such as Pax4, Pax6, and BETA2. These homeobox genes might play important roles in the intestinal phenotypic expression of endocrine cells and gastrointestinal carcinoid tumors of hindgut origin.

In the present study, no rectal carcinoid tumors gave rise to metastatic lesions, such as liver and lungs. Further studies are needed to clarify the association the End-cell marker expression and the metastasis/progression of rectal carcinoid tumors.

In conclusion, most rectal carcinoid tumors exhibited the e-GI type, suggesting the importance of gastric End-cell marker expression for histogenesis of the rectal carcinoid tumors. Further studies of pathological and biological analyses are needed to clarify the histogenesis of the carcinoid tumors.

\section{Acknowledgements}

We thank Miss Yukimi Ito for expert technical assistance and Dr Malcolm A. Moore for revision of the scientific English language. This study was supported by a Grant-in-Aid for Young Scientists (B) (19790490) from the Ministry of Education, Culture, Sports, Science and Technology of Japan.

\section{References}

1. Nishikura K, Watanabe H, Iwafuchi M, Fujiwara T, Kojima K and Ajioka Y: Carcinogenesis of gastric endocrine cell carcinoma: analysis of histopathology and p53 gene alteration. Gastric Cancer 6: 203-209, 2003. 
2. Hamilton SR and Aaltonen LA: Pathology and Genetics, Tumours of the Digestive System. WHO, IARC Press, Lyon, 2000.

3. Rindi G, Kloppel G, Alhman H, et al: TNM staging for foregut (neuro)endocrine tumors: a consensus proposal including a grading system. Virchows Arch 449: 395-401, 2006.

4. Ramage JK, Davies AHG, Ardill J, et al: Guideline for the management of gastroenteropancreatic neuroendocrine (including carcinoid) tumors. Gut 54: 1-16, 2005.

5. Modlin IM and Sandor A: An analysis of 8305 cases of carcinoid tumors. Cancer 79: 813-829, 1997.

6. Takenaka Y, Tsukamoto T, Mizoshita T, et al: Gastric and intestinal phenotypic correlation between exocrine and endocrine components in human stomach tumors. Histol Histopathol 22: 273-284, 2007.

7. Sjolund K, Sanden G, Hakanson R and Sundler F: Endocrine cells in human intestine: an immunocytochemical study. Gastroenterology 85: 1120-1130, 1983.

8. Owen DA: Normal histology of the stomach. Am J Surg Pathol 10: 48-61, 1986

9. Hocker M and Wiedenmann B: Molecular mechanisms of enteroendocrine differentiation. Ann NY Acad Sci 859: 160-174, 1998.

10. Oberg K: Gastric neuroendocrine cells and secretory products. Yale J Biol Med 71: 149-154, 1998.

11. Otsuka T, Tsukamoto T, Mizoshita T, et al: Coexistence of gastric- and intestinal-type endocrine cells in gastric and intestinal mixed intestinal metaplasia of the human stomach. Pathol Int 55: 170-179, 2005.

12. Tahara E, Haizuka S, Kodama $\mathrm{T}$ and Yamada A: The relationship of gastrointestinal endocrine cells to gastric epithelial changes with special reference to gastric cancer. Acta Pathol Jpn 25: 161-177, 1975.

13. Nishikura K, Watanabe H, Iwafuchi M, Ajioka Y, Hayashidate H and Tanabe T: Histological overview of the classification of gastric carcinoid (in Japanese with English summary). Stomach Intestine 35: 1349-1354, 2000.

14. Solcia E, Kloppel G and Sobin LH: Histological typing of endocrine tumors. WHO International Histological Classification of Tumors. 2nd edition, Springer Verlag, Berlin, pp61-68, 2000 .

15. Tatematsu M, Tsukamoto $T$ and Inada K: Stem cells and gastric cancer: role of gastric and intestinal mixed intestinal metaplasia. Cancer Sci 94: 135-141, 2003.
16. Mizoshita T, Tsukamoto T, Nakanishi $\mathrm{H}$, et al: Expression of $\mathrm{Cdx} 2$ and the phenotype of advanced gastric cancers: relationship with prognosis. J Cancer Res Clin Oncol 129: 727-734, 2003.

17. Tsukamoto T, Mizoshita T, Mihara M, et al: Sox 2 expression in human stomach adenocarcinomas with gastric and gastric-andintestinal-mixed phenotypes. Histopathology 46: 649-658, 2005.

18. Mizoshita T, Tsukamoto T, Inada KI, et al: Loss of MUC2 expression correlates with progression along the adenomacarcinoma sequence pathway as well as de novo carcinogenesis in the colon. Histol Histopathol 22: 251-260, 2007.

19. Raju GC and Lee YS: Gastrointestinal carcinoid tumours: histological, histochemical and immunohistochemical study. Ann Acad Med Singapore 17: 81-88, 1988

20. Federspiel BH, Burke AP, Sobin LH and Shekitka KM: Rectal and colonic carcinoids. A clinicopathologic study of 84 cases. Cancer 65: 135-140, 1990.

21. Moyana TN and Satkunam N: Crypt cell proliferative micronests in rectal carcinoids. An immunohistochemical study. Am J Surg Pathol 17: 350-356, 1993.

22. Iwashita A, Haraoka S, Ikeda K, et al: Clinicopathological study on carcinoid tumor of the rectum-Mainly on comparison of cases with metastasis and those without metastasis (in Japanese with English summary). Stomach Intestine 40: 151-162, 2005.

23. Koike M, Inada K, Nakanishi H, Matsuura A, Nakamura S and Tatematsu M: Cellular differentiation status of epithelial polyps of the colorectum: the gastric foveolar cell-type in hyperplastic polyps. Histopathology 42: 357-364, 2003.

24. Hirono $\mathrm{H}$, Ajioka $\mathrm{Y}$, Watanabe $\mathrm{H}$, et al: Bidirectional gastric differentiation in cellular mucin phenotype (foveolar and pyloric) in serrated adenoma and hyperplastic polyp of the colorectum. Pathol Int 54: 401-407, 2004.

25. Jaffee IM, Rahmani M, Singhal MG and Younes M: Expression of the intestinal transcription factor CDX2 in carcinoid tumors is a marker of midgut origin. Arch Pathol Lab Med 130: 1522-1526, 2006.

26. Jenny M, Uhl C, Roche C, et al: Neurogenin3 is differentially required for endocrine cell fate specification in the intestinal and gastric epithelium. EMBO J 21: 6338-6347, 2002.

27. Schonhoff SE, Giel-Moloney M and Leiter AB: Minireview: Development and differentiation of gut endocrine cells. Endocrinology 145: 2639-2644, 2004. 